\title{
Costs of Surgical Site Infections That Appear after Hospital Discharge
}

\section{Nicholas Graves, ${ }^{\star} \dagger$ Kate Halton, ${ }^{*} \dagger$ Merrilyn Curtis, ${ }^{*}$ Shane Doidge, ${ }^{*}$ David Lairson, $\neq$ Marylou McLaws, $\S$ and Michael Whitby*}

Data were collected from surgical patients in the hospital and on 4 occasions postdischarge. The incidence of postdischarge surgical site infection was $8.46 \%$. Strong evidence showed that these infections caused minor additional costs, which contradicts existing literature. We discuss why previous studies might have overstated costs.

$\mathrm{M}$ ost cases of healthcare-acquired surgical site infections (SSI) appear after discharge from hospital (1); rates of postdischarge SSI between $2 \%$ and $14 \%$ have been reported (2). Little is known of the costs of postdischarge SSI, but 2 studies suggest that they are large (3-5) with health services and patients incurring costs and subsequent production losses. The combination of high frequency and high cost suggests that programs that reduce the risks of postdischarge SSI should be adopted, but decision makers should assess the cost-effectiveness of additional prevention efforts. This exercise requires valid estimates of the change in costs and benefits from additional prevention programs $(6,7)$. Understanding the costs of postdischarge SSI is therefore essential. The work completed so far is valuable but demonstrates some methodologic weaknesses. Plowman et al. $(3,4)$ assessed only patient-reported signs and symptoms of postdischarge SSI, and Perencevich et al. (5) relied on routine healthcare records for diagnosis/surveillance and matched case patients with controls on only 3 confounding variables.

Our study assessed the costs of postdischarge SSI. We adopted a societal perspective and included the costs incurred by healthcare services, private costs, and production losses. The research method was chosen to address the suggested weaknesses of the studies of Plowman et al. $(3,4)$ and Perencevich et al. (5).

*The Centre for Healthcare Related Infection Surveillance and Prevention, Brisbane, Queensland, Australia; †Queensland University of Technology, Brisbane, Queensland, Australia; fUniversity of Texas Health Science Center at Houston, Houston, Texas, USA; and §University of New South Wales, Sydney, New South Wales, Australia

\section{The Study}

We recruited, in consecutive order, adults ( $>18$ years of age) admitted to 3 Australian hospitals in 2004 for knee or hip prostheses, cardiovascular procedures, femoropopliteal bypass grafts, or abdominal procedures, including abdominal hysterectomies and lower segment caesarean sections. Four infection-control research nurses recruited participants and collected data during the hospital admission process and on 4 separate occasions after surgery by visiting the patients in their homes (data collection is illustrated in the Figure). Monetary estimates of all costs were made by multiplying frequency with a cost vector for the item of service (9-12). Production losses were estimated by comparing the presurgery level of (unwaged and waged) productive activity with the actual level of (unwaged and waged) productive activity achieved during the 4 weeks postdischarge. These losses were converted to a monetary value by using market prices for labor, approximated by average pretax earnings (13).

The question we address is whether postdischarge SSIs independently affect costs. The specific cost outcomes we seek to explain are listed in online Appendix 1 (available from http://www.cdc.gov/ncidod/EID/vol12no05/05-1321 _app1.htm). Adjustment was made for other factors believed to influence these cost outcomes (i.e., confounding factors); these included the type of surgical procedure, duration of surgery, American Society of Anesthesiologists score, wound class, number of coexisting conditions, length of hospital stay, whether patient was funded by the public sector or private insurance, admitting hospital, sex, age, ethnicity, patient's socioeconomic status (14), whether the patient was in waged employment, salary level and health-related quality of life as measured by the SF-12v2 Health Survey (available from http://www.sf-36.org/ tools/sf12.shtml) scores at baseline and 4 weeks postdischarge. The complete set of explanatory variables available for analyses and the summary statistics are presented in Table 1 and online Appendix 2 (available at http:// www.cdc.gov/ncidod/EID/vol12no05/05-1321_app2 .htm). Because the outcome variables were continuous and linear, ordinary least squares regression was chosen to model the independent effect of SSI on cost outcomes (Table 2). See online Appendix 3 (available at http://www. cdc.gov/ncidod/EID/vol12no05/05-1321_app3.htm) for a description of the statistical analyses.

The mean age of the 449 patients included in the analyses was 63.65 years (SD 14.34), and 50.56\% were women. The mean length of hospital stay for the sample was 7.8 days (SD 8.68, median 6 days, interquartile range 4-8). Thirty-eight of the 449 patients included in the study had a diagnosis of SSI postdischarge, which indicates an incidence of $8.46 \%$ for the 8-month period during which patients were recruited. A higher proportion of persons 


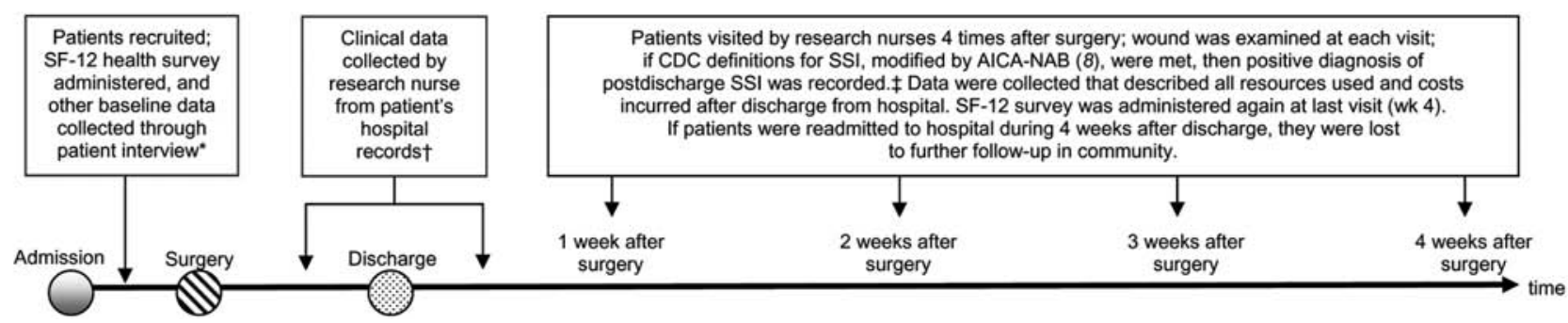

Figure. The timing and nature of data collection. *Interview questions available from author on request. †Types of data collected from patient hospital records available from author on request. $¥$ Variables collected from patient at each nurse visit are available from author on request. CDC, Centers for Disease Control and Prevention; SSI, surgical site infection; AICA-NAB, Australian Infection Control Association-National Advisory Board.

with SSI (18.24\%) compared to those without SSI (2.43\%) were readmitted to the hospital, but the mean lengths of stay of the readmitted persons were similar, 16.57 days versus 15.72 days, respectively. Summary statistics for all variables are included in Table 1 and in online Appendix 2, and the ICD-10 procedures for the 38 cases of SSI are described in online Appendix 4 (available at http://www. cdc.gov/ncidod/EID/vol12no05/05-1321_app4.htm).

No evidence was found of multicollinearity or interactions between variables. However, none of the outcome variables were normally distributed, and variance of the error term was not constant (i.e., heteroscedastic), so all models were estimated by using the Huber-White covari- ance matrix (15). Results of the ordinary least squares regressions are summarized in online Appendix 1. Strong statistical evidence shows that postdischarge SSI independently causes the following: 1.36 extra contacts with community-based services with increased costs of $\$ 47.78$; 6.46 days of additional antimicrobial drug therapy with increased costs of $\$ 14.44$; and an increase in total health service costs of AU $\$ 74$ (US \$57) when the costs of readmission to the hospital are excluded and AU \$123 (US \$94) when the costs of readmission to the hospital are included. The strength of the relationship between SSI and all other cost outcomes was not significant with the $95 \%$ confidence interval crossing zero for all other models.

\begin{tabular}{|c|c|c|}
\hline \multirow[b]{2}{*}{ Characteristic } & \multicolumn{2}{|c|}{$\%$ (no.) } \\
\hline & No SSI $(n=411)$ & $S S I(n=38)$ \\
\hline Age, y, mean (SD) & $63.58(14.41)$ & $64.37(13.72)$ \\
\hline Socioeconomic score $(1-100),{ }^{*}$ mean (SD) & $35.67(19.17)$ & $40.37(20.53)$ \\
\hline Male & $48.66(199)$ & $57.89(22)$ \\
\hline \multicolumn{3}{|l|}{ Recruiting hospital } \\
\hline 280-bed district hospital & $35.04(144)$ & $47.37(18)$ \\
\hline 712-bed teaching hospital & $47.45(195)$ & $36.84(14)$ \\
\hline 156-bed district hospital & $16.79(69)$ & $15.79(6)$ \\
\hline \multicolumn{3}{|l|}{ Income } \\
\hline Currently in waged employment & $20.68(85)$ & $31.58(12)$ \\
\hline$\leq \$ 50,000 / y$ & $12.41(51)$ & $23.68(9)$ \\
\hline$>\$ 50,000 / y$ & $2.68(11)$ & $5.26(2)$ \\
\hline Refused to answer & $5.35(22)$ & $2.63(1)$ \\
\hline \multicolumn{3}{|l|}{ Education } \\
\hline Left school at $\leq 15 \mathrm{y}$ & $60.83(250)$ & $63.16(24)$ \\
\hline Left school at $16-18$ y & $7.54(31)$ & $13.16(5)$ \\
\hline Some form of higher education & $30.41(125)$ & $23.68(9)$ \\
\hline \multicolumn{3}{|l|}{ Ethnicity } \\
\hline Caucasian & $96.11(395)$ & $97.37(37)$ \\
\hline Aboriginal & $0.24(1)$ & $0.00(0)$ \\
\hline Asian & $0.24(1)$ & $0.00(0)$ \\
\hline Other & $2.43(10)$ & $2.63(1)$ \\
\hline \multicolumn{3}{|l|}{ How patient was funded } \\
\hline Public & $91.97(378)$ & $94.74(36)$ \\
\hline Intermediate & $6.81(28)$ & $5.26(2)$ \\
\hline Private & $0.24(1)$ & $0.00(0)$ \\
\hline
\end{tabular}




\begin{tabular}{|c|c|c|}
\hline \multirow[b]{2}{*}{ Outcome } & \multicolumn{2}{|c|}{ Mean (SD) } \\
\hline & No SSI, $n=411$ & $\mathrm{SSI}, \mathrm{n}=38$ \\
\hline \multicolumn{3}{|l|}{ Healthcare services } \\
\hline No. contacts with hospital-based services in 4 wk PD & $1.10(1.68)$ & $1.11(1.43)$ \\
\hline Cost of contacts with hospital-based services in 4 wk PD (\$) & $40(60)$ & $40(52)$ \\
\hline No. contacts with community-based services in 4 wk PD & $1.85(2.72)$ & $3.13(3.04)$ \\
\hline Cost of contacts with community-based services in 4 wk PD (\$) & $62(103)$ & $105(111)$ \\
\hline No. tests/swabs & $0.48(1.43)$ & $0.71(1.27)$ \\
\hline Costs of tests/swabs $(\$)$ & $11(35)$ & $16(28)$ \\
\hline No. of days on antimicrobial drugs during 4 wk PD & $0.96(3.10)$ & $6.76(8.23)$ \\
\hline Costs of antimicrobial drugs & $2.16(9.08)$ & $14.47(19.96)$ \\
\hline Sum of all costs incurred by health care services, excluding costs of readmission (\$) & $115(128)$ & $176(144)$ \\
\hline Sum of all costs incurred by health care services, including costs of readmission ( $\$$ ) & $417(3050)$ & $2,361(8,811)$ \\
\hline \multicolumn{3}{|l|}{ Production losses } \\
\hline Patient production losses during 4 wk PD (min) & $5,237(5,488)$ & $7,295(6,349)$ \\
\hline Monetary valuation of patient production losses $(\$)$ & $1,895(1,986)$ & $2,640(2,298)$ \\
\hline Informal care givers production losses during 4 wk PD & $1,630(2,329)$ & $2,863(3,168)$ \\
\hline Monetary valuation of Informal care giver production losses $(\$)$ & $590(843)$ & $1,036(1,146)$ \\
\hline \multicolumn{3}{|l|}{ Private costs } \\
\hline Time patient spent accessing hospital services (min) & $169(444)$ & $184(338)$ \\
\hline Time patient spent accessing community-based services (min) & $129(410)$ & $282.76(528.14)$ \\
\hline Total out-of-pocket expenditures during 4 wk PD (\$) & $5(19)$ & $4(21)$ \\
\hline SF-12 Physical Component Summary (enrollment) & $39.15(11.76)$ & $37.63(12.24)$ \\
\hline SF-12 Mental Component Summary (enrollment) & $50.37(10.06)$ & $48.87(10.60)$ \\
\hline SF-12 Physical Component Summary (wk 4) & $39.03(8.84)$ & $37.68(8.04)$ \\
\hline SF-12 Mental Component Summary (wk 4) & $53.92(8.35)$ & $52.06(11.10)$ \\
\hline
\end{tabular}

\section{Conclusions}

These results support the view that most SSIs first appear after discharge from hospital, but we did not find any evidence that postdischarge SSI causes substantial economic costs even when costs are viewed from a societal perspective. These findings contradict Perencevich et al. (5), who found the economic cost of a case of SSI diagnosed after discharge was almost 50 -fold the estimate we report here. Thus, what might explain this extreme discrepancy in attributed costs? The study designs and research methods differed. Compared to Perencevich et al. (5), we used more control variables (described in Tables 1 and Online Appendix 2 and listed below the table in Appendix 1). Might this extended set of control variables reduce bias from omitted variables and so reduce the cost attributed to SSI? Another factor might be the surveillance method. Perencevich et al. (5) used automated record screening that relied on accurate documentation of diagnostic, testing, or treatment codes and pharmacy records. This process resulted in 89 diagnoses among 4,571 patients, an incidence rate of $1.9 \%$. For our study, patients were recruited before surgery and infection-control research-nurses visited the patients in their homes on 4 occasions after discharge, during which time the wound was examined and the definition of the Centers for Disease Control and Prevention definition, modified by the Australian Infection Control Association Inc., was applied (8). This method yielded a much higher infection rate of $8.38 \%$. One interpretation is that the surveillance method used by Perencevich et al. was not sensitive to all cases of postdischarge SSI. Instead, only those that generated certain data items in the downstream electronic records were flagged, and these may have been the most serious cases of SSI that generated the greatest costs. This theory might be supported by the higher rate of readmission among the patients with cases of SSI in the Perencevich data (34\%) compared to the rate in our study (18\%).

Of course, other factors may have an influence, such as the case mix and socioeconomic characteristics of the participants, the costs of the inputs to healthcare services (i.e., salaries for doctors and nurses), consumer preferences (i.e., for more or less postdischarge care), and predefined care protocols.

Also, our data only describe a 4-week period after surgery and not the 8 -week period considered by Perencevich et al. (5). We recommend that readers interpret our results carefully but nevertheless suggest that the economic costs of SSIs that occur after hospital discharge are real but not substantial.

The Centre for Healthcare Related Infection Surveillance and Prevention, Queensland Health, provided funding to the Queensland University of Technology for the development and publication of this research. 
Dr Graves is a senior research fellow in health economics with a joint appointment in the School of Public Health, Queensland University of Technology, and the Centre for Healthcare Related Infection Control and Surveillance, Princess Alexandra Hospital, Brisbane. His research interests include all aspects of the economics of hospital infection and other chronic and infectious diseases.

\section{References}

1. Holtz TH, Wenzel RP. Postdischarge surveillance for nosocomial wound infection. A brief review and commentary. Am J Infect Control. 1992;20:206-13.

2. Kent P, McDonald M, Harris O, Mason T, Spelman D. Post-discharge surgical wound infection surveillance in. A provincial hospital: follow-up rates, validity of data and review of the literature. ANZ J Surg. 2001;71:583-9.

3. Plowman RP, Graves N, Griffin M, Roberts JA, Swan AV, Cookson BC, et al., The socioeconomic burden of hospital acquired infection. London: Public Health Laboratory Service; 1999.

4. Plowman RP, Graves N, Griffin MAS, Roberts JA, Swan AV, Cookson B, et al. The rate and cost of hospital-acquired infections occurring in patients admitted to selected specialties of a district general hospital in England and the national burden imposed. J Hosp Infect. 2001;47:198-209.

5. Perencevich EN, Sands KE, Cosgrove SE, Guadagnoli E, Meara E, Platt R. Health and economic impact of surgical site infections diagnosed after hospital discharge. Emerg Infect Dis. 2003;9:196-203.

6. Graves N, Halton K, Lairson D. Economics and preventing hospitalacquired infection-broadening the perspective. Infect Control Hosp Epidemiol. In press.
7. Graves N. Economics and preventing hospital-acquired infection. Emerg Infect Dis. 2004; 10:561-6.

8. Aurich E, Borgert J, Butler M, Cadwallader H, Collignon P, Eades M, et al. Introduction to Australian surveillance definitions: surgical site infections and bloodstream infections. Australian Infection Control. 2000;5:25-31.

9. The Australian Government, Department of Health and Ageing. Manual of resource items and their associated costs for use in submissions to the Pharmaceutical Benefits Advisory Committee involving economic evaluation [cited 2005 Mar] (available fromhttp:// www.health.gov.au/internet/wcms/publishing.nsf/Content/healthpbs-general-pubs-manual-content.htm, ed). Canberra, Australia: Department of Health and Ageing; 2004.

10. MIMS online [cited March 2005]. Available from http://www. mims.hcn.net.au/ifmx-nsapi/mims-data/?MIval=2MIMS_ssearch\#

11. Australian Institute of Health and Welfare. Australian hospital statistics 2001-2002. Canberra, Australia: Australian Institute of Health and Welfare; 2003.

12. The Australian Government, Department of Health and Ageing. Medicare benefits schedule book. Canberra, Australia: Department of Health and Ageing; 2004.

13. Australian Bureau of Statistics. Average weekly earnings. Canberra, Australia: Australian Bureau of Statistics; 2004.

14. Jones FL, McMillan J. Scoring occupational categories for social research: a review of current practice with Australian examples. Work, Employment and Society. 2001;15:539-63.

15. White $\mathrm{H}$. A heteroscedasticity-consistent covariance matrix estimator and a direct test for heteroscedasticity. Econometrica. 1980;48:817-38.

Address for correspondence: Nicholas Graves, School of Public Health, Queensland University of Technology, Victoria Park Rd, Kelvin Grove, QLD 4059, Queensland, Australia; email: n.graves@qut.edu.au

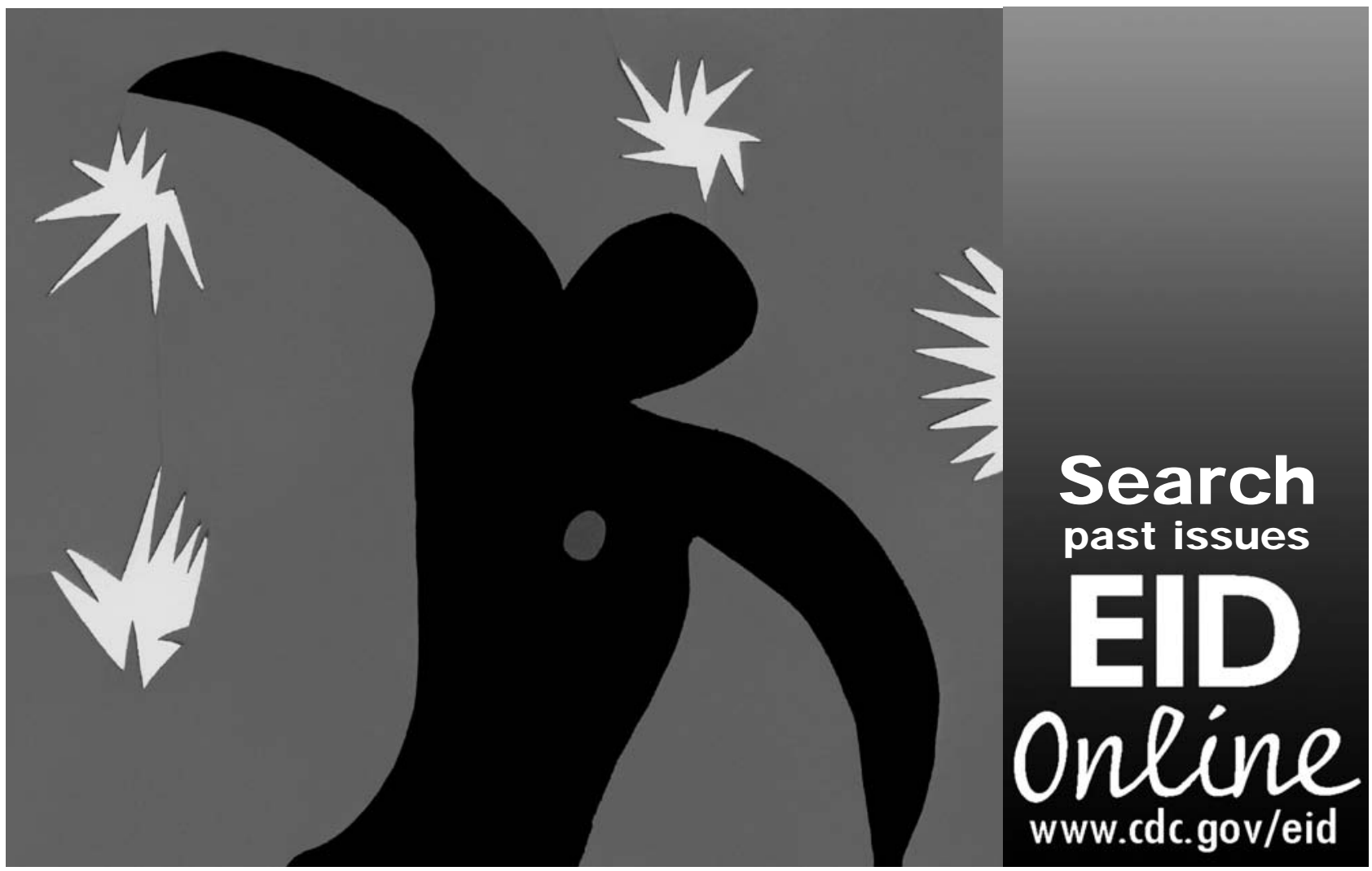

